\title{
Terminal voltage and power regulation using vehicle-to-grid (V2G) schemes integrated to smart interconnected power system
}

Tarek Hassan Mohamed, Abdel-moamen Mohammed Abdel-Rahim

Departement of Electrical Engineering, Faculty of Energy Engineering, Aswan University, Egypt

\begin{tabular}{|c|c|}
\hline Article Info & ABSTRACT \\
\hline Article history: & \multirow{6}{*}{$\begin{array}{l}\text { This paper is an attempt to use the vehicle-to-grid (V2G) connected system } \\
\text { to play an effective job in the regulation of the voltage and power of the } \\
\text { power system besides its positive effect for the system frequency. A two area } \\
\text { power system is used to measure the effectiveness of the proposed V2G } \\
\text { scheme. The proposed system is tested under the step load change condition } \\
\text { and three phase short system case. A comparison between the system with } \\
\text { proposed V2G schemes and that system without V2Gs is carried out showing } \\
\text { the importance of the presence of the V2G schemes on system frequency, } \\
\text { terminal voltage and total power. MATLAB /SIMULINK software package } \\
\text { is used as a test environment. }\end{array}$} \\
\hline Received April 12, 2018 & \\
\hline Revised Aug 20, 2018 & \\
\hline Accepted Dec 14, 2018 & \\
\hline Keywords: & \\
\hline $\begin{array}{l}\text { Interconnected power system } \\
\text { Plug-in electric vehicle }\end{array}$ & \\
\hline
\end{tabular}

Smart grid

Third keyword

Vehicle to grid system

Copyright $@ 2019$ Institute of Advanced Engineering and Science. All rights reserved.

\section{Corresponding Author:}

Tarek Hassan Mohamed

Departement of Electrical Engineering,

Faculty of Energy Engineering, Aswan University

sahary, Aswan University, 51825, Aswan, Egypt.

Email: tarekhie@aswu.edu.eg

\section{INTRODUCTION}

Nowadays, problems such as insecure with unscheduled power flows and higher losses led transmission power systems to be larger and complex. The power engineers made efforts to keep the reliable operation of the power system and to keep stable electricity from the generators to the customers.

Recently, light has been shed on electric vehicles as a power storage source for emergency use during plug-in schedule period. However, installing of the controllable loads such as plug-in EVs in smart grids has been increased $[1,2]$. On the other hand, vehicle-to-grid (V2G) scheme can be defined by the concept of injecting power back into the grid from Electric Vehicle (EV) batteries.For their characteristics (such as containing of lithium-ion battery), the trends to use the plug-in EVs in clean power systems.

V2G smart scheme is concerned with the benefit from electrical vehicles EVs during plug in period which pre-scheduled by car owners to assure their convenience. For car owners, they can save about $13.6 \%$ of charging costs due to discharging their excess stored energy back to the grid during the time of high electricity price. For the Grid side, V2G in the power system can deal with the problem of load changes or unstable renewable energy, which lead to frequency deviations [3].

On the other hand, problems of voltage instability are attracting increasing attention in power systems. The terminal voltage and generated or transmitted power are fluctuating depending on load variation and according to the output of renewable sources. Many techniques used to deal with such problems such as flexible AC transmission system (FACTS), static synchronous compensator and (STATCOM) superconducting magnetic energy storage (SMES). 
Most of the past publication about utilizing EV's or V2G schemes in power systems discussed only their benefits on frequency regulation issue [4-7]. The issue of $V 2 G$ capacity in case of frequency regulation service is discussed in [4]. V2G has been presented as a frequency regulator in [5]. In [6] using a prototype, the centralized load frequency control (LFC) and further fast demand response schemes are being demonstrated by coordinating remote systems via Ethernet communication. Also in [7], A centralized control scheme allocating the LFC signals to the thermal power generations and EVs have been proposed.

In [8], an attempt to study the effect of the V2G scheme on the voltage and power control but only for a single area power system. Like the control methods of photovoltaic PV systems [12-13], V2G has been applied to solve the penetrations resulted from PVs.

This paper discusses the effect of the presence of V2G systems on terminal voltage adaptation and regulation of the system power under step load demand and three phase fault condition. A two-area power system includes the proposed V2G scheme has been tested through a three-phase step load changes and the fault of three phase short circuit using computer simulation. Matlab/Simulink program simulation tests have been made to discuss the effect of the presence of $\mathrm{V} 2 \mathrm{G}$ scheme integrated into the interconnected system (in cases of step load changes and fault condition) on:

a. System frequency.

b. Terminal voltages of the system.

c. Active and reactive power.

This paper is organized as follows. Section 2 describes smart grid with EVs Section 3 presents V2G system, Simplified battery model is presented in 4 and section 5 discusses the system under study. Section 6 presents the detailed parameters of the system under study. Seven for the proposed power system and analyzes time-domain simulated results of three phase resistive load disturbance and three phase short circuit in the studied system. And finally, conclusions are drawn in Section 8.

\section{SMART GRID WITH EVs}

To get more effective, flexible and lower cost operation, the Smart Grid is considered as an opportunity to use the ICTs (Information and Communication Technologies) for monitoring and control throughout the power system [8]. The European Technology Platform [9] defines the Smart Grid as: "A Smart Grid is an electricity network that can intelligently integrate the actions of all users connected to it generators, consumers and those that do both - in order to efficiently deliver sustainable, economic and secure electricity supplies."

Many countries are moving towards changing their power systems to smart networks, for example, in Japan, Since the Tohoku earthquake on 2011, the light has been shed on Smart Grid as a method for both of reconstruction of the damaged districts and development of a low-carbon society.

On the other hand, EVs have been attracted much attention for the reduction of $\mathrm{CO} 2$ emissions in transportation systems. With respect to the BLUE Map plan, the worldwide needs for electricity to charge EVs will reach $2500 \mathrm{TWh}$ in 2050 [10].

Large-capacity batteries used in EVs, leading them to be a form of distributed energy storage. Plugin EVs are those which can be charged in the home, these plug-in EV's can be helpful in case of load shifting. Therefore, two-way communication technologies will be used to integrate the EVs into the electricity supply in the form of smart grid networks, this what can be called "vehicle-to-grid" (V2G) [11]. Figure 1 shows V2G scheme integrated into a smart interconnected power system.

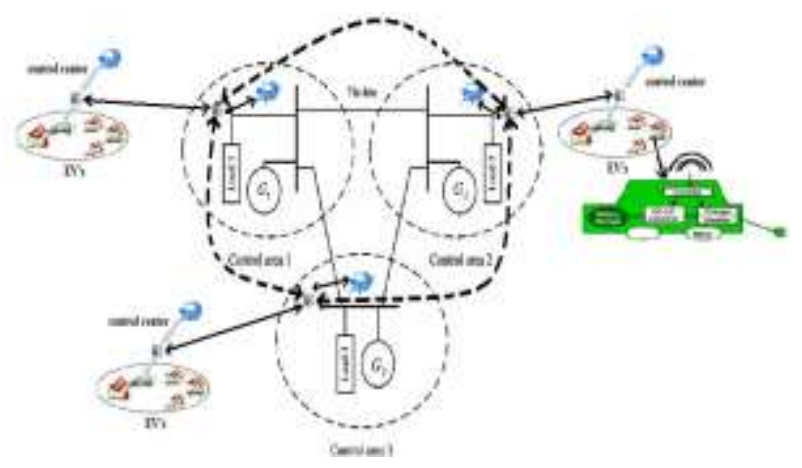

Figure 1. Smart interconnected power system with V2G scheme 


\section{V2G SMART SCHEME}

The idea of the V2G smart scheme is to get benefit from electrical vehicles EVs during plug in period, this period is pre-scheduled by car users to confirm their convenience. The main aim of usage of V2G in the power system is to deal with the problem of load changes and fluctuations results from renewable energy sources which lead to frequency deviations, terminal voltage variation and changes in transmitted power, so, the presence of V2G scheme will enhance the total system response during the periods of load disturbances and or fluctuations of renewable power sources. As shown in Figure 2, the output power of battery in V2G scheme can be positive (discharging) or negative (charging) according to the sign and the value of the frequency deviation $\left(\Delta f=f_{\text {actual }}-f_{\text {reference }}\right)$ as shown in the following (7):

$$
P_{V 2 G}=\left\{\begin{array}{c}
K_{V 2 G} \cdot \Delta f\left(K_{V 2 G} \cdot \Delta f \leq P_{\max }\right) \\
P_{\max }\left(P_{\max }<\left|K_{V 2 G} \cdot \Delta f\right|\right)
\end{array}\right.
$$

and considering a balance battery (charging/discharging) control, V2G gain $K_{V 2 G}$ can be calculated from

$$
K_{V 2 G}=K_{\max }\left\{1-\left(\frac{{\operatorname{SOC}-S O C_{\text {low }(\text { high })}}_{\operatorname{SOC} \max (\min )}-\operatorname{SOC}_{\text {low }(\text { high })}}{{ }^{n}}\right\}\right.
$$

where all parameters in (1) have been designed as the state of charge (SOC) is balanced around $50 \%$, as shown in Figure 3

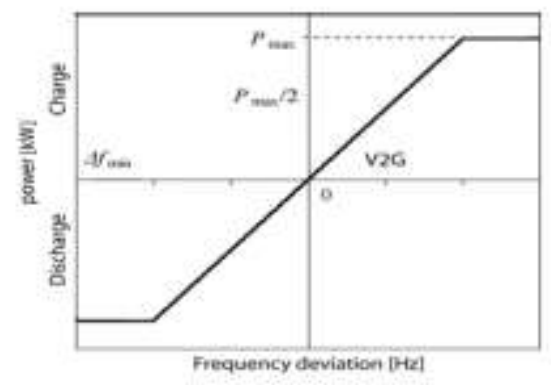

(a)

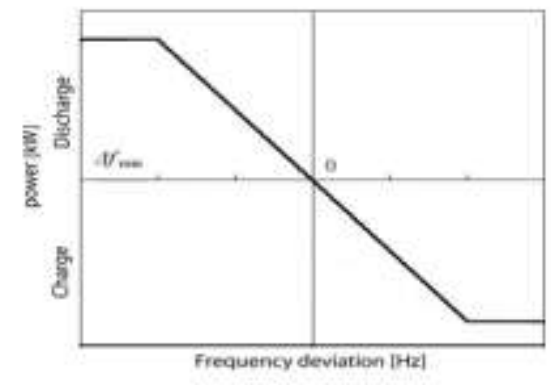

(b)

Figure 2. Curve of V2G power/frequency deviation: (a) Input power to V2G and (b) Output power from $\mathrm{V} 2 \mathrm{G}$

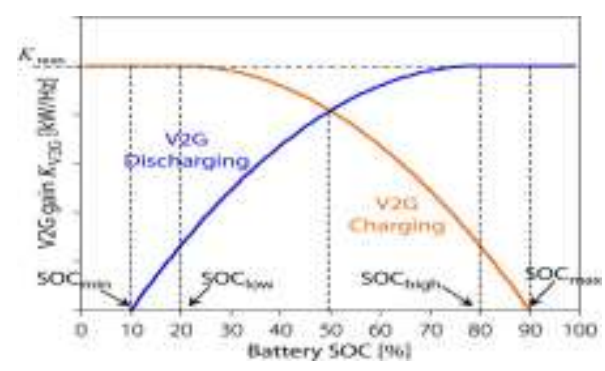

Figure 3. Balance control of battery SOC

\section{SIMPLIFIED BATTERY MODEL}

A simplified battery model is considered in this paper, this model is consisting of a voltage source which consists of open circuit voltage OCV and internal resistance Rint [7], the V2G power (PV2G) can be calculated from:

$$
P_{V 2 G}=O C V . I+R_{\text {int }} . I^{2}
$$

Where I represent the current of charging/discharging operation. In addition, the Nernst equation is used to calculate the OCV: 


$$
O C V=V_{\text {nom }}+\alpha \frac{R_{0} T}{F} \ln \left(\frac{S O C}{C_{n o m}-S O C}\right)
$$

and SOC can be updated from:

$$
\frac{d S O C}{d t}=\eta I
$$

Substituting 3 in 5 yields:

$$
\frac{d S O C}{d t}=\eta\left(-O C V+\sqrt{O C V^{2}-4 R_{\text {int }} P_{V 2 G}} / 2 R_{\text {int }}\right)
$$

also, the energy (E) needed to charge the battery to the destination SOC (SOCd) from SOCi at any instant (i) can be get from:

$$
\begin{aligned}
& E=\int_{S_{S O C}}^{S O C_{d}} O C V d S O C= \\
& V_{\text {nom }}\left(S O C_{d}-S O C_{i}\right)+\alpha C_{n o m} \ln \left(\frac{C_{\text {nom }}-S O C_{d}}{C_{\text {nom }}-S O C_{i}}\right)+\alpha S O C_{d}\left(\frac{S_{O C C_{d}}}{C_{n o m}-S O C_{d}}\right)-\alpha S O C_{i}\left(\frac{\text { SOC }_{i}}{C_{\text {nom }}-S O C_{i}}\right)
\end{aligned}
$$

\section{UNDER STUDY SYSTEM}

As shown in Figure 4, the system under study in this paper consists of two area power system, each area has one diesel generator and loads, V2G scheme is connected with area 1 at bus number 2 ("load11" plus the V2G system ), area 2 has two loads at bus number 4 (directly connected load "Load22", while "Load 21 " is connected by a controlled switch). The two areas are connected by two series symmetric line, each line has $20 \mathrm{~km}$ length, in addition, each area has one step down transformer which used to connect the area loads.

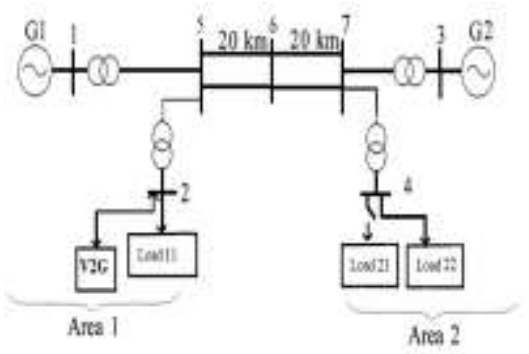

Figure 4. Simple Two-Area Power System

\section{SYSTEM CONFIGURATION}

This paper used a two-area power system shown in Figure 4, this system is represented using Matlab/Simulink software. Area 1 has a 15MW diesel generator, 4MW electric vehicles (four aggregated V2G schemes with detailed parameters listed in table 1 and the battery parameters are illustrated in tables 2, 3 ) and 10MW residential load (with 0.16 pf). Area 2 has 4MW direct connected load ("Load22") and 4 MW controlled load ("Load21"). Each area has $25 \mathrm{kv} / 600 \mathrm{v}$ step down transformer.

Table 1. Parameters of the V2G schemes

\begin{tabular}{cccc}
\hline Unit number & Number of cars* & Initial state of charge [\%] & Charging/Regulation mode \\
\hline 1 & 35 & $90 \%$ & Regulation \\
2 & 25 & $90 \%$ & Regulation \\
3 & 10 & $90 \%$ & Regulation \\
4 & 20 & $90 \%$ & Regulation \\
5 & 10 & $0 \%$ & Regulation \\
\hline$*$ The rated power of each car is $40 \mathrm{~kW}$ & & \\
\hline
\end{tabular}


Table 2. Parameters of V2G control

$\begin{array}{ll}\text { Maximum V2G power (Pmax) [kw] } & 40^{*} \\ \text { Maximum V2G gain (Kmax) [kw/Hz] } & 200 \\ \text { n, SOCmin, SOClow, SOChigh, SOCmax [\%] } & 2,10,20,80,90 \\ \left(\Delta f_{\min }\right)[\mathrm{Hz}] & -0.1\end{array}$

$*(8$ batteries, $5 \mathrm{kw} /$ battery $)$

Table 3 Specifications of battery model

\begin{tabular}{ll}
\hline Nominal voltage $\left(\mathrm{V}_{\text {nom }}\right)[\mathrm{V}]$ & 345.6 \\
Nominal capacity $\left(\mathrm{C}_{\mathrm{nom}}\right)[\mathrm{Ah}]$ & 15 \\
Energy Capacity $[\mathrm{kwh}]$ & 5.2 \\
Internal resistance $(\mathrm{Rint})[\Omega]$ & 0.4 \\
Sensitivity parameter of OCV-SOC $(\alpha)$ & 15 \\
Current efficiency $(\eta)$ & 1.0 \\
\hline
\end{tabular}

\section{RESULTS AND DISCUSSIONS}

The test environment used in this paper is Matlab/Simulink software package. In addition, all simulation periods at the plug in hours of the electric vehicles hours (usually between 10 PM to 6 AM). Two cases are considered in this paper to test the efficiently of presence the proposed V2G scheme. In the first case of study, the system is checked under the condition of a step load change at Area2 (4MW three phase resistive controlled load will be switched on at $t=40 \mathrm{sec}$ ). Figure 5 shows the simulation results of the system with and without V2G schemes. For Figure 5, the results from the top to the bottom are the terminal voltage, load current, total power, active and reactive power (all of the residential load, "load11"). It is clear from the figure that with the proposed V2G schemes, the terminal voltage goes steady state more damping and with a small value of overshoot. It is reported that also the load current is improved in both transient and steady-state cases. In addition, the load active and reactive powers have improved as a result of the participation of V2G schemes. (without V2G, the overshoot and rise time are bigger than those of the system with of $\mathrm{V} 2 \mathrm{G}$ schemes for all three signals). Also, as shown in Figure 6, the rotor speeds of G1 shown in Figure 6.a and G2 shown in Figure 6.b are more damped in case of presence of V2G schemes (both of the undershoot and the rise time have been damped to about 50\%). In brief, it has been noted that the V2G schemes succeeded in improving the performance of the system. moreover, Figure 7 shows the state of charge of the aggregated group number 3 (according to Table 1). While the total output power of V2G is shown in Figure 8. (the gain $K_{V 2 G}$ is kept at constant value $K_{V 2 G}=200$, this because the initial state of charge SOC of V2G unit 1, unit 2, unit 3, unit 4 have been chosen as $90 \%$, while SOC of unit 5 equal to $0 \%$ as shown in Table 2 and Table 3).

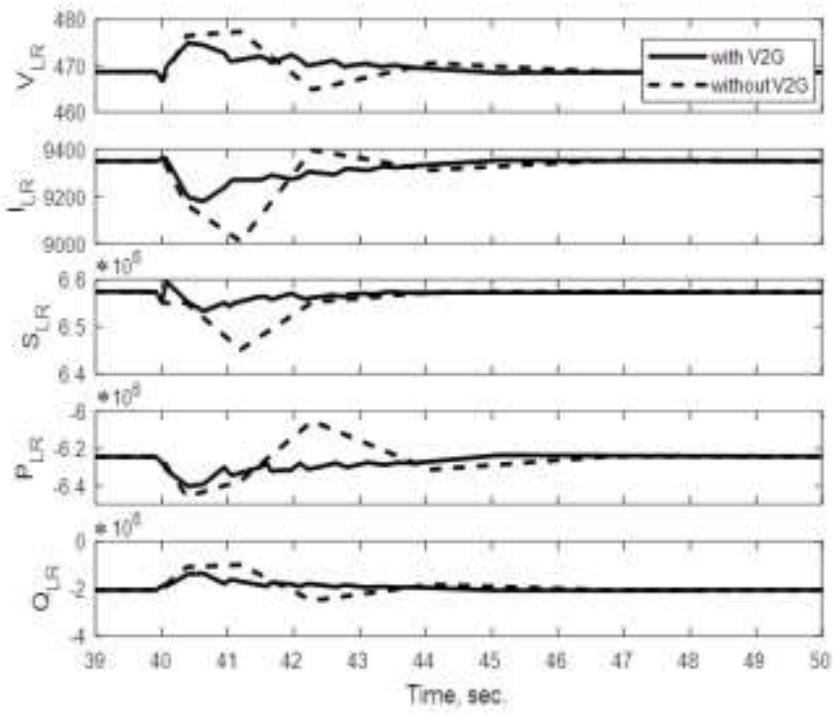

Figure 5. System response for the case of step load change 


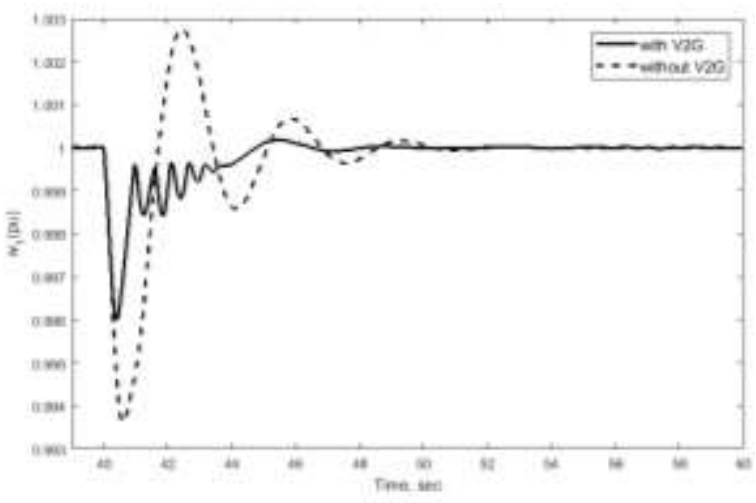

(a)

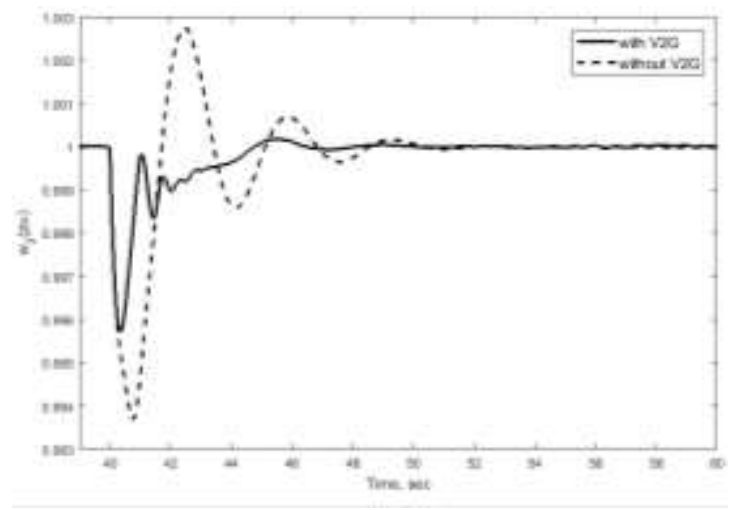

(b)

Figure 6. Rotor speed response for the case of step load change: a) Rotor speed of G1, b) Rotor speed of G2

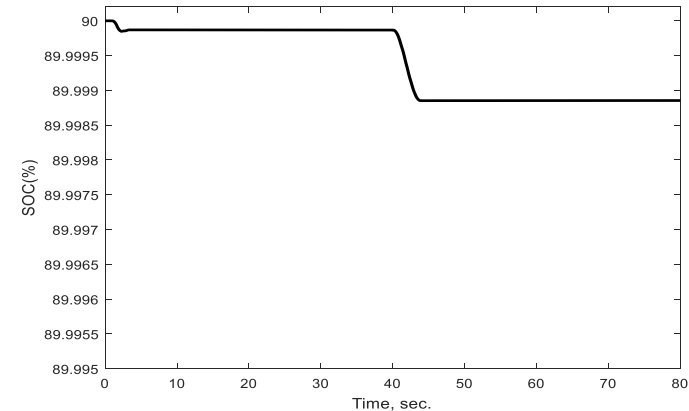

Figure 7. The State of charge of the aggregated group number 3

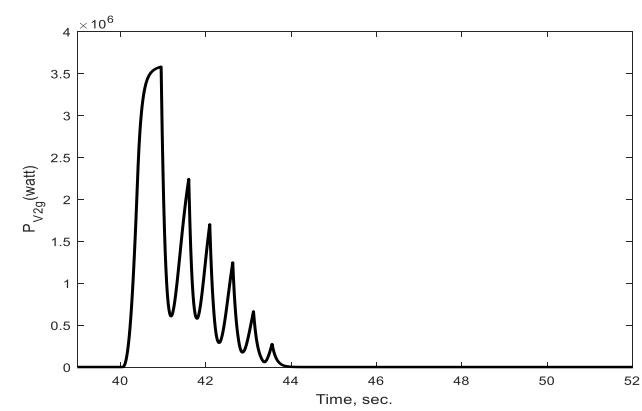

Figure 8. The total output power of V2G schemes

In the second case of study, system is tested in case of a short circuit between all of the three-phases and ground at the middle of the distance between the two areas (at bus number 6 ) for a short period starts at $t=50$ sec. and disappears at $t=(50+6.5 / 60)$ sec. The results of the proposed system are compared with the system without V2G schemes as shown in Figure 9. It is clear from Figure 10 that the proposed system with V2G schemes is superior to the system without V2G schemes, giving significantly more damping to terminal load voltage, load current, load active and reactive powers. Figure 10 shows the results of the frequency responses of the system, this figure supports the importance of the presence of the V2G schemes in system frequency regulation.

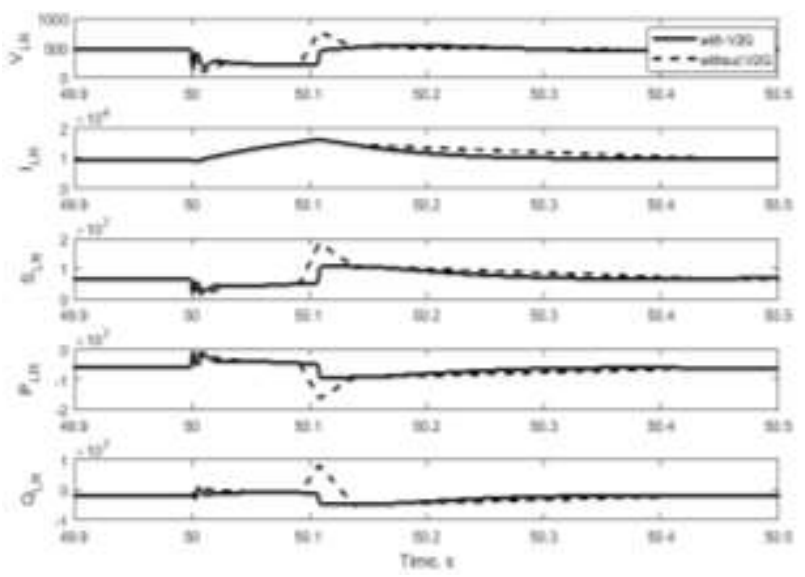

Figure 9. System response for the case of three phase short circuit 


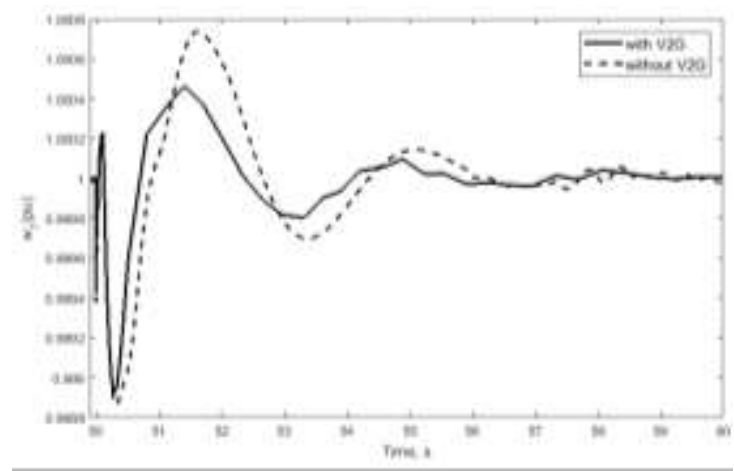

(a)

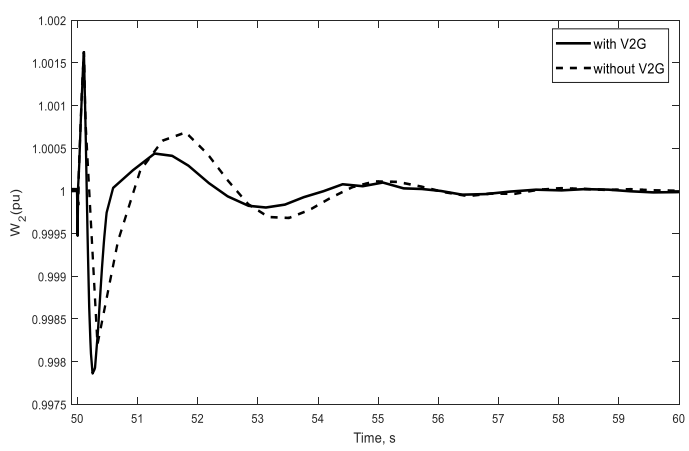

(b)

Figure 10. Rotor speed response for the second case of study: a) Rotor speed of G1, b) Rotor speed of G2

\section{CONCLUSION}

The rapid technology of electric vehicles has guided to numerous challenges to power system operation. Moreover, a plug-in electric vehicle can play either as a load or as a power source by applying the V2G technology. In this paper, a certain effect of the presence of V2G schemes in the performance of a small two-area power system such as frequency, terminal voltages, and the power. Digital simulations have been used to validate the effectiveness of the interconnected power system with the proposed V2G schemes. The system with proposed V2G schemes has been tested through a step load change and three phase faults at the connection line. Results supported that during the moment of step load demands or 3 phase short-circuits, the presence of $\mathrm{V} 2 \mathrm{G}$ schemes has a positive effect not only on system frequency but also on the terminal load voltages, active and reactive power. A comparison between the proposed system with V2G and the system without V2G schemes is carried out assuring the superiority of the system with the proposed V2G schemes. Applying V2G to three area large scale power system is considered the future work of this study.

\section{REFERENCES}

[1] D. C. Das, A. Roy and N. Sinha, "GA based frequency controller for solar thermal-diesel-wind hybrid energy generation/energy storage system," International Journal of Electrical Power \& Energy Systems, vol. 43, no. 1, pp. 262-279, 2012.

[2] H. R. Najafia and F. Dastyarb, "Dynamic maximum available power of fixed-speed wind turbine at islanding operation," International Journal of Electrical Power \& Energy Systems, vol. 47, pp. 147-156, May 2013.

[3] S. Vachirasricirikula and I. Ngamroo, "Robust controller design of heat pump and plug-in hybrid electric vehicle for frequency control in a smart microgrid based on specified-structure mixed H2/Hœ control technique," Applied Energy, vol. 88, no. 11, pp. 3860-3868, 2011.

[4] A. Y. S. Lam, K. Leung and V. O. K. Li, "Capacity Estimation for Vehicle-to-Grid Frequency Regulation Services With Smart Charging Mechanism," in IEEE Transactions on Smart Grid, vol. 7, no. 1, pp. 156-166, Jan. 2016.

[5] S. Han, S. Han and K. Sezaki, "Estimation of Achievable Power Capacity From Plug-in Electric Vehicles for V2G Frequency Regulation: Case Studies for Market Participation," in IEEE Transactions on Smart Grid, vol. 2, no. 4, pp. 632-641, Dec. 2011.

[6] Y. Ota, H. Taniguchi, J. Baba, A. Yokoyama "Implementation of autonomous distributed V2G to electric vehicle and DC charging system, " Electric Power Systems Research, vol. 120, no. 11, p. p 177 -183, March 2015.

[7] Y. Ota, H. Taniguchi, T. Nakajima, K. M. Liyanage, J. Baba and A. Yokoyama, "Autonomous Distributed V2G (Vehicle-to-Grid) Satisfying Scheduled Charging," in IEEE Transactions on Smart Grid, vol. 3, no. 1, pp. 559-564, March 2012.

[8] Tarek Hassan Mohamed, and Abdel-Moamen M. A. "Single Area power system voltage and frequency control using V2G scheme," $19^{\text {th }}$ Middle East Power Systems Conference, MEPCON' 2017, Helwan University, Cairo , Egypt, December 2017.

[9] European Commission, "European SmartGrids Technology Platform: Vision and Strategy for Europe's Electricity," 2006.

[10] Inage, S., "Modelling Load Shifting Using Electric Vehicles in a Smart Grid Environment", IEA Energy Papers, OECD Publishing, Paris, 2010.

[11] J. Tan and L. Wang, "A Game-Theoretic Framework for Vehicle-to-Grid Frequency Regulation Considering Smart Charging Mechanism," in IEEE Transactions on Smart Grid, vol. 8, no. 5, pp. 2358-2369, Sept. 2017.

[12] Arjyadhara Pradhan, Bhagbat Panda, "Experimental Analysis of Factors Affecting the Power Output of the PV Module," International Journal of Electrical and Computer Engineering, vol. 7, no. 6, pp. 3190 - 3197, Dec. 2017.

[13] R.S. Ravi Sankar, S.V. Jayaram Kumar, and G. Mohan Rao, "Adaptive Fuzzy PI Current Control of Grid Interact PV Inverter," International Journal of Electrical and Computer Engineering, vol. 8, no. 1, pp. 472-482, Feb. 2018. 


\section{BIOGRAPHY OF AUTHORS}

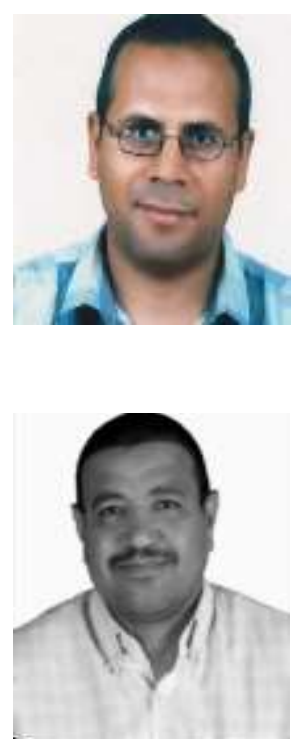

Tarek Hassan Mohamed, was born in Libya on. January 1975. He received his B.s degree in Automatic control from Faculty of electronics, Minofia, Egypt, in 1997, and M.Sc. ,and PhD from Faculty of Engineering, Minia University, Egypt, in 2006, 2012 respectively $\mathrm{He}$ is a member of the Faculty of Energy Engineering, Aswan University, Egypt

Abdel-Moamen M. Abdel-Rahim obtained his B.Sc. and M.Sc. degrees from Assuit University, Egypt and Ph.D. degree from Indian Institute of Technology (IIT), Roorkee, India, all in Electrical Engineering in 1991, 1998 and 2004 respectively. He joined High Institute of Energy, South Valley University, Aswan, Egypt as an Assistant Professor from 2005; He is presently working as Assistant Professor in the Department of Electrical Engineering, Faculty of Engineering, South Valley University, Qena, Egypt. His field of interest is Power System Operation, Control and Optimization Problems including FACTS devices. He is a member of IEEE. 